\title{
The role of immunohistochemistry in the diagnosis of hyalinizing clear cell carcinoma of the minor salivary gland: a case report
}

\author{
G. Lai, ${ }^{1}$ S. Nemolato, ${ }^{2}$ S. Lecca, ${ }^{3}$ G. Parodo, ${ }^{2}$ C. Medda, ${ }^{1}$ G. Faa ${ }^{2}$ \\ ${ }^{1}$ Department of Otorhinolaryngology, and ${ }^{3}$ Pathology ASL n. 7, Carbonia; ${ }^{2}$ Department of \\ Cytomorphology, Section of Pathology, University of Cagliari, Cagliari, Italy
}

\begin{abstract}
C2008 European Journal of Histochemistry
A case of hyalinizing clear cell carcinoma (HCCC) of the minor salivary glands of the oral cavity is reported. A 52year-old woman presented with a growing mass at the base of the tongue. The patient underwent complete resection of the tumour. The histological picture was characterized by trabeculae or solid nests of proliferating cells with a clear cytoplasm, surrounded by a hyalinizing stroma. Tumour cells were immunoreactive for Cytokeratins 5, 6, 7, 8, 14, 17 and 18. No reactivity was observed for cytokeratin 20 , vimentin, S100 protein, smooth-muscle actin, muscle-specific actin, and calponin. These findings confirmed the diagnosis of HCCC of minor salivary glands of the oral cavity. The clinical presentation, the immunohistochemical pattern and the role of cytokeratins in the differential diagnosis of HCCC are discussed with a review of the literature.
\end{abstract}

Key words: clear cell carcinoma, salivary glands, cytokeratins, immunocytochemistry.

Correspondence: Giuseppe Lai, Istituto di Anatomia Patologica, Ospedale San Giovanni di Dio, via Ospedale 46, Cagliari, 09124 Italy. Tel.: +39.329.4908082 +39.070237302.

Fax: +39.070 .657882$

E-mail: lai13@libero.it

Paper accepted on September 23, 2007

European Journal of Histochemistry 2008; vol. 52 issue 4 (October-December):251-254
$\mathrm{H}$ yalinizing clear cell carcinoma (HCCC) is a rare low grade tumour of minor salivary glands (Suzuki et al., 2006), first described in 1994 (Milchgrub et al., 1994), and accounting for about $1 \%$ of intra-oral salivary gland tumours (Buchner et al., 2007). Predominantly middle aged women are struck by this tumour, presenting with a "pauci-symptomatic" mass localized most often at the oral cavity and pharynx (Chao et al., 2004), less frequently at parotid glands and other sites of the larynx (Wang et al., 2002). Low-grade biological behaviour with slow and indolent growth are the most important features of this tumour (Suzuki et al., 2006; Wang et al., 2002). The local recurrence rate is $17 \%$ (Wang et al., 2002); multiple recurrences have only been occasionally reported (Tang et al., 1995). The rare cases with local and lung metastases have been sensitive to chemotherapy, with favorable clinical behaviour and no recurrences during followup (Wang et al., 2002; Grenevicki et al., 2001). To date, only one case of HCCC with more aggressive behaviour, quick tumour growth, diffuse metastases and unfortunate prognosis, a few months, has been reported (O'Regan et al., 2004).

The main distinctive microscopic feature of HCCC is the presence of round to polygonal epithelial cells with a clear cytoplasm rich in glycogen, organized in trabeculae, cords, or solid nests surrounded by an abundant hyalinizing fibrocollagenous stroma (Suzuki et al., 2006; Milchgrub et al., 1994; Sicurella et al., 2004). Intratumoral necrotic areas may be present (Sicurella et al., 2004). Mitoses are infrequent or absent (Wang et al., 2002; Urban et al., 1996); a high mitotic count was only reported in a case presenting with lymph node metastases (Milchgrub et al., 1994). Lymphatic and perineural invasion is observed in most cases (Milchgrub et al., 1994; Wang et al., 2002; Urban et al., 1996). The immunohistochemical pattern of the tumor is characterized by immunoreactivity for low molecular weight cytokeratins, epithelial membrane antigen (EMA), 
and carcinoembrionic antigen (CEA). Vimentin, S100 protein, Smooth-muscle actin, Muscle-specific actin, and calponin are not expressed (Milchgrub et al., 1994; Wang et al., 2002; Sicurella et al., 2004; Urban et al., 1996).

Several entities should be considered in the differential diagnosis of HCCC, including other primary clear cell carcinomas of the salivary glands, like epithelial-myoepithelial carcinoma (EMCC) (Milchgrub et al., 1994; Wang et al., 2002; Batsakis 1980; Batsakis et al., 1983), low-grade mucoepidermoid carcinoma (Milchgrub et al., 1994; Wang et al., 2002), oncocytoma (Milchgrub et al., 1994), and metastases from renal cell carcinoma and melanoma (Milchgrub et al., 1994).

In this study we report a case of hyalinizing clear cell carcinoma of the minor salivary glands arising at the base of the tongue. The clinical, pathological and immunohistochemical features are analyzed, with particular attention to the role of cytokeratins in the differential diagnosis of this tumour entity.

\section{Materials and Methods}

A 52 year-old caucasian woman presented to our hospital with a history of an asymptomatic mass which had been localized at the base of the tongue for several months. On oral cavity observation, a well localized mass, reddish in colour, about $2 \mathrm{~cm}$ in diameter, was observed. At clinical examination, the tumour showed a parenchimatous consistence. It was covered by a slightly hyperemic mucosa, and was not painful. No cervical lymph nodes were palpable. The patient underwent complete resection of the tumour. Multiple tumour samples were formalin-fixed and routinely processed. 3 micron paraffin sections were stained with Hematoxylin and Eosin and immunostained with commercial antibodies against CK5, CK6, CK7, CK8/18, CK14, CK17, CKAE1/AE3, CK19, CK20, Vimentin, S100 protein, Alfa-SMA, Calponin and Ki67.

\section{Results}

Histopathological examination revealed a uniform population of polymorphic, round to polygonal tumour cells with a clear cytoplasm, polymorphic vacuoleted nuclei with evident nucleoli, arranged in trabeculae or solid nests, surrounded by a hyalinized stroma (Figure 1). Focally cystic spaces containing eosinophilic, serous material were observed. PAS stain showed the presence of glycogen in the cytoplasm of clear cells. Apoptotic bodies were seen, scattered among tumour cells (Figure 2). No mitotic figures were observed. The tumour was surrounded by a fibrous capsule which resulted focally infiltrated. Multiple foci of vascular invasion were detected outside the tumour capsule (Figure 3). The immunohistochemical pattern was characterized by immunoreactivity for CK5, CK6, CK7, CK8/18, CK14, CK17, CK19, CKAE1/AE3 (Figures 4, 5, 6, 7, 8). Immunoreactivity for $C K 7$ was strong and diffuse while immunostaining for the other markers was focal. No reactivity was detected for $\mathrm{CK} 20$, Vimentin, S100, Alfa-SMA, Calponin. Ki67 showed nuclear himmunoreactivity in less then $5 \%$ of tumour cells. Further clinical examinations were undertaken to check for the presence of other primary tumours: CTscan of kidneys did not show any renal mass. Based on these findings, the tumour was diagnosed as HCCC.

At 12 months follow-up there is no evidence of recurrent disease or metastases.

\section{Discussion}

Primary clear cell tumours of salivary glands comprise a subgroup of salivary neoplasias which are distinct in terms of histogenesis, tumour biology and clinical behaviour (Wang et al., 2002). The differential diagnosis of clear cell salivary neoplasms encompasses a broad range of possibilities (Seifert 1996), including epithelial-myoepithelial carcinoma (EMEC) (Batsakis et al., 1992; Kawahara et al., 2004), clear cell variants of myoepithelial carcinoma (Savera et al., 2000), acinic cell carcinoma (Ellis 1998), oncocytoma (Ellis 1988), and low and intermediate grade mucoepidermoid carcinoma (Brandwein et al., 2000). Metastases of renal cell tumour should also be excluded (Simpson et al., 1990). In clinical practice, the diagnostic term "clear cell carcinoma" is a diagnosis of exclusion, applied only after other specific tumours with clear cell morphology are excluded (Suzuki et al., 2007).

In the differential diagnosis among different clear cell tumours, histology is often of little use mainly when no definitive evidence of myoepithelial differentiation is found, due to the high morphological similarities observed in the different "clear cell" entities 


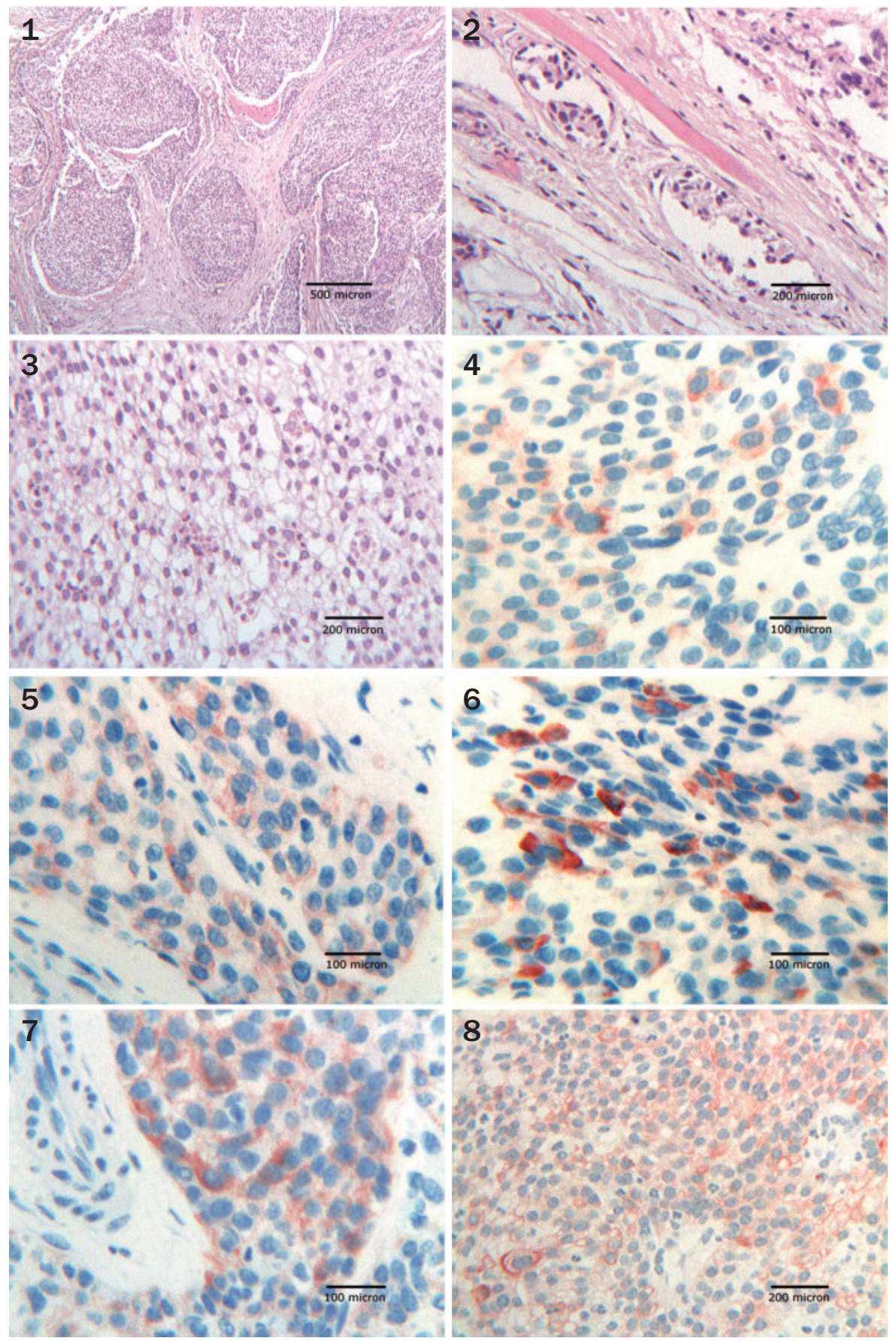

Figure 1. H-E; original magnification $x$ 100. Tumour cells arranged in solid nest or pod-like structures surrounded by abundant hyalinizing stroma. Figure 2. H-E; original magnification $\times 250$. Diffuse proliferation of clear cells with apoptotic bodies.

Figure 3. H-E; original magnification $x$ 250. Vascular invasion outside the tumour capsule.

Figure 4. CK17; original magnification $x$ 400. Focal cytoplasmic immunostaining of tumour cells. Figure 5. CK14; original magnification x 400. Granular cytoplasmic imunoreactivity in the majority of tumour cells.

Figure 6. CK5; original magnifiction $x$ 400. Strong cytoplasmic and membranous immunostaining associated with focal perinuclear Golgian reactivity.

Figure 7. CK7: original magnification $\times 400$.Strong cytoplasmic immunohistochemical staining.

Figure 8 CK18; original magnification $x$ 250. Diffuse membranous immunoreactivity.

(Kawahara et al., 2004). On the other hand, immunocitochemistry may be helpful in revealing the cell of origin of the tumour. Myoepithelial carcinoma shows immunoreactivity of tumour cells for S-100 protein and for vimentin in $100 \%$ of cases, variably associated with immunolabelling for CK7, CK14, SMA and calponin (Savera et al., 2000). Epithelialmyoepithelial carcinoma shows a positive reaction to S-100 protein, muscle specific actin, associated with immunoreactivity for EMA and cytokeratins AE1/AE3 (Wang et al., 2002; Kawahara et al., 2004). Acinic cell carcinoma cells strongly react with CK7, while CK14 is typically not expressed (Chu and Weiss, 2002). Mucoepidermoid carcinoma shows immunoreactivity for CK7, CK8/18, CK14, CK17 and CK19 (Chu and Weiss, 2002).

The immunohistochemical pattern of the present case was characterized by a diffuse reactivity for 
CK5, CK7, CK8/18 and by focal reactivity for CK6, CK17 and CK14; only scattered cells showed immunoreactivity for CK19, in the absence of immunolabelling for CK20, S-100 protein, actin and vimentin. This pattern appears specific for HCCC due to the unique association of basal cell markers ( $C K 5)$ with myoepithelial markers (CK6, CK14), cytokeratins typical of duct epithelia (CK19), markers of glandular origin (CK7), and with markers of secretory and parenchymatous cells (CK8/18). The diagnosis of myoepithelial carcinoma was ruled out by the lack of expression of actin (Nagao et al., 1998, Savera et al., 2000). The diagnosis of acinic cell carcinoma was unlikely because of immunoreactivity in the present case, for $\mathrm{CK} 14$, never expressed in acinic cell carcinoma. The possibility of a solitary metastasis from a tumour arising from kidney was excluded by the expression, in our case, of CK7, constantly not expressed in this tumour (Chu and Weiss, 2002; Nikitakis et al., 2004). The possibility of a squamocellular carcinoma of the oral cavity spreading to the salivary glands was ruled out by diffuse immunoreactivity in the present case for $\mathrm{CK} 7$, normally absent or focally and weakly expressed in squamocellular carcinoma (Nikitakis et al., 2004; Regauer et al., 2000). Mucoepidermoid carcinoma remains the only tumour of the salivary glands to show an immunohistochemical profile very similar to that observed in our case, excepting the expression of CK20 found in $20 \%$ of these tumours (Nikitakis et al., 2004). The absence of globet cells, negativity of tumour cells for mucin staining and the absence of areas of squamous differentiation in our case allowed us to exclude this diagnosis (Milchgrub et al., 1994; Suzuki et al., 2007).

In conclusion, for diagnostic purposes, the immunohistochemical pattern of the present case could be suggested, when confirmed in a large series of HCCC, as a useful tool in the diagnosis of HCCC of minor salivary glands.

\section{Acknowledgments}

We express our deep gratitude to Prof. Raf Sciot (K.U. Leuven) and Prof. Matteo Fraschini (University of Cagliari) for critical suggestions.

We also thank Mr. Ignazio Ferru for secretarial assistance and Mrs. Sandra Serra for technical support.

\section{References}

Batsakis JG. Clear cell tumors of salivary glands. Ann Otol Rhinol Laryngol 1980;89:196-7.

Batsakis JG, Kraemer BB, Sciubba JJ. The pathology of head and neck tumors: the myoepithelial cells and its participation in salivary gland neoplasia, part 17. Head Neck Surg 1983;5:222-33.

Batsakis JG, EI-Naggar AK, Luna MA. Pathology consultation: epithelial myoepithelial carcinoma of salivary glands. Ann Otol Rhinol Laryngol 1992;101:540-2.

Brandwein M, Hille JJ, Gnepp D, Urken ML, Ivanov K. The many faces of epidermoid carcinoma. Brandwein M.

Buchner A, Merrell PW, Carpenter WM. Relative frequency of intra-oral salivary gland tumors: a study of 380 cases from northern California and comparison to reports from other parts of the world. J Oral Pathol Med 2007;36:207-14.

Chao TK, Tsai CC, Yeh SY, Teh JE. Hyalinizing clear cell carcinoma of the hard palate. J Laryngol Otol 2004;118:382-4.

Chu PG, Weiss LM. Keratin expression in human tissues and neoplasms. Histopathology 2002;40:403-39.

Ellis GL. "Clear cell" oncocytomas of salivary glands. Hum Pathol 1988;19:862-7.

Ellis GL. Clear cell neoplasms in salivary glands: clearly a diagnostic challenge. Ann Diagn Pathol 1998;2:61-78.

Grenevicki LF, Barker BF, Fiorella RM, Mosby EL. Clear cell carcinoma of the palate. Int J Oral Maxillofac Surg 2001;30:452-4.

Kawahara A, Harada H, Yokoyama T, Kage M. Cytopathological features of an epithelial-myoepithelial carcinoma with predominant clear myoepithelial cells in the parotid gland. Diagn Cytopathol 2004;30:280-3.

Milchgrub S, Gnepp DR, Vuitch F, Delgado R, Albores-Saavedra J. Hyalinizing clear cell carcinoma of salivary glands. Am J Surg Pathol 1994; 18:74-82.

Nagao T, Sugano I, Ishida $Y$, Tajima $Y$, Matsuzaki 0 , Konno A, et al. Salivary gland malignant myoepithelioma: a clinicopathologic and immunohistochemical study of ten cases. Cancer 1998;83:1292-9.

Nikitakis GN, Tosios KI, Papanikolaou SV, Rivera H, Papanicolaou SI, Ioffe OB. Immunohistochemical expression of cytokeratins 7 and 20 in malignant salivary gland tumors. Modern Pathology 2004;17:407-15.

0’Regan E, Shandilya M, Gnepp DR, Timon C, Toner M. Hyalinizing clear cell carcinoma of salivary gland: an aggressive variant. Oral Oncology 2004; 40:348-52

Regauer S, Beham A, Mannweiler S. CK7 expression in carcinomas of the Waldeyer's ring area. Hum Pathol 2000;31:1096-101.

Savera AT, Sloman A, Huvos AG, Klimstra DS. Myoepithelial carcinoma of the salivary glands: a clinicopathological study of 25 patients. Am J Surg Pathol 2000;24:761-74.

Seifert G. Classification and differential diagnosis of clear and basal cell tumors of the salivary glands. Semin Diagn Pathol 1996;13:95-103.

Sicurella $F$, Gregorio A, Stival P, Brenna A. Clear cell carcinoma of minor salivary gland of the tongue. Acta Otorhinolaryngol Ital 2004;24:157-60.

Simpson RH, Sarsfield PT, Clarke T, Babajews AV. Clear cell carcinoma of minor salivary glands. Histopathology 1990;17:433-8.

Suzuki $H$, Katoh A, Udaka T, Shiomori T, Fujimura T, Fujimura K, et al. Hyalinizing clear cell carcinoma arising from the base of the tongue. Acta Otolaryngol 2006;126: 653-6.

Suzuki H, Yamauchi G, Hashimoto K. Clear cell carcinoma of the mandibular gingiva minor salivary gland: a case report with immunohistochemical study. Oral Surg Oral Med Oral Pathol Oral Radiol Endod 2007;103:36-40.

Tang SK, Wan SK, Chan JK. Hyalinizing clear cell carcinoma of salivary gland: report of a case with multiple recurrences over 12 years. Am J Surg Pathol 1995;19:240-1.

Urban SD, Keith DA, Goodman M. Hyalinizing clear cell carcinoma: report of a case. J Oral Pathol Med 1996;25:562-4.

Wang B, Brandwein M, Gordon R, Robinson R, Urken ML, Zarbo RJ. Primary salivary clear cell tumors a diagnostic approach: a clinicopathologic and immunohistochemical study of 20 patients with clear cell carcinoma, clear cell myoepithelial carcinoma, and epithelialmyoepithelial carcinoma. Arch Pathol Lab Med 2002;126:676-85. 